\title{
Geståo visual de projetos audiovisuais: aprimorando o processo criativo do design de produção
}

Juliana Krupahtz

Mestranda, Universidade Federal de Santa Catarina / juliana.krupahtz@gmail.com Orcid: 0000-0002-5494-0116 / lattes

\section{Leandro Werner}

Doutorando, Universidade Federal de Santa Catarina (UFSC) / makakowerner@gmail.com Orcid: 0000-0003-3120-7074 / lattes

Julio Monteiro Teixeira

Doutor, Universidade Federal de Santa Catarina (UFSC) / juliomontex@gmail.com $\underline{\text { lattes }}$

Enviado: 22/08/2020 // Aceito: 12/12/2020 


\title{
Gestão visual de projetos audiovisuais: aprimorando o processo criativo do design de produção
}

\begin{abstract}
RESUMO
O projeto audiovisual engloba inúmeros profissionais diferentes em ações que precisam ser coordenadas. Para que estas ações tenham maior fluidez, pode-se fazer uso da gestão visual de projetos. Este artigo tem como objetivo aprimorar um esquema proposto por Krupahtz (2018) utilizando a gestão visual de projetos. Para isto inicialmente foram contextualizadas as áreas de design de produção e gestão visual de projetos para tornar claro a interação entre elas e como abordagem metodológica foi utilizado o método Lemming, de Teixeira (2018). Como resultado apresenta-se o processo de elaboração de um modelo visual de acordo com o método e a criação de um painel visual que contempla a fase de pré-produção, com enfoque no design de produção audiovisual. Nas considerações finais são abordadas sugestões para trabalhos futuros e potenciais interessantes para pesquisas envolvendo as duas áreas.
\end{abstract}

Palavras-chave: gestão visual de projetos. audiovisual. design de produção. 


\title{
Visual management of audiovisual projects: improving the creative process of production design
}

\begin{abstract}
The audiovisual project involves countless different professionals in actions that need to be coordinated. For these actions to be more fluid, visual project management can be used. This article aims to improve the scheme proposed by Krupahtz (2018) using visual project management. For this purpose, the areas of production design and visual project management were contextualized to make clear the interaction between them. As a methodological approach, it was used the Lemming method, by Teixeira (2018). As the result, there is the elaboration process of a visual model according to the method and it is described the creation of a visual panel that contemplates the pre-production phase, with a focus on production design. In the final considerations, it is made some suggestions for future works and presented some interesting potentials for research involving both areas.
\end{abstract}

Keywords: project visual management. filmmaking. production design. 


\title{
Gestión visual de proyectos audiovisuales: mejora del proceso creativo del diseño de producción
}

\begin{abstract}
RESUMEN
El proyecto audiovisual implica un sinnúmero de profesionales de diferentes acciones en que necesitan ser coordinados. Para que estas acciones sean más fluidas, se puede utilizar la gestión visual de proyectos. Este artículo tiene como objetivo mejorar un esquema propuesto por Krupahtz (2018) utilizando la gestión visual de proyectos. Para este fin, las áreas de diseño de producción y gestión de proyectos visuales fueron contextualizados para dejar en claro la interacción entre ellos y como un enfoque metodológico, el método Lemming, por Teixeira (2018), se utilizó. Como resultado, se presenta el proceso de elaboración de un modelo visual según el método y la creación de un panel visual que contempla la fase de preproducción, con foco en el diseño de producción audiovisual. En las consideraciones finales, se discuten sugerencias para trabajos futuros y potenciales interesantes para la investigación en ambas áreas.
\end{abstract}

Palabras clave: manejo visual de proyectos. audiovisual. diseño de producción. 


\section{INTRODUÇÃO}

Um projeto audiovisual pode ser de diferentes naturezas e finalidades, englobando a criação de produtos como filmes, séries, documentários, videoclipes, vídeos artísticos, publicitários, institucionais ou jornalísticos. Em qualquer um desses casos, principalmente nos de produtos ficcionais, o processo de criação audiovisual pode ser considerado um processo criativo, que envolve fases, etapas e tarefas específicas atribuídos a uma equipe de projeto.

Uma equipe de audiovisual pode ser composta de várias maneiras conforme o tamanho e a complexidade do produto. Em situações ideais, como coordenador do departamento de arte encontra-se o designer de produção, responsável pelo projeto visual do filme juntamente com o diretor de arte. Conforme os autores Grove (2004) e LoBrutto (2002), a definição da função do diretor de arte é a execução da criação, enquanto o designer de produção planeja e participa da concepção do filme, organizando juntamente com o diretor, produtor, diretor de fotografia e roteirista, toda a criação visual que for necessária para o projeto acontecer.

Desta forma, entende-se que o recorte da criação de um projeto audiovisual feito pelo designer de produção pode ser considerado como um projeto de design (KRUPAHTZ, 2018), necessitando então de um processo que seja lógico e de fácil entendimento por todos. Sendo assim, a gestão visual de projetos pode aprimorar os processos e a visualização de etapas e tarefas, principalmente em casos de projetos mais complexos.

A gestão visual de projetos pode auxiliar na comunicação e direcionamento de uma equipe de audiovisual. Sua principal funcionalidade encontra-se em tornar visível a todos, de maneira clara e simples, informações pertinentes ao 
desenvolvimento do projeto.

Outro propósito que se pode encontrar na gestão visual de projetos é a melhoria da comunicação, tanto em colaboradores como também entre líderes e colaboradores. Este tipo de gestão é capaz de promover a rápida comunicação de eventos simultâneos que estão ocorrendo em uma ambiente de produção (MARTINS, 2006).

Esta organização visual dos projetos também é capaz de auxiliar na disposição, planejamento, melhoria contínua e controle das ações, principalmente quando existe a necessidade de diversos times multidisciplinares trabalharem em conjunto. A gestão visual permite a rápida compreensão e visualização do fluxo de trabalho, padronizando assim a aderência e os processos (LEAN INSTITUTE BRASIL, 2012).

Em um projeto audiovisual a gestão visual pode auxiliar e servir como um guia para a condução do projeto, mantendoo sempre conectado à sua finalidade principal.

Nesta pesquisa, partiu-se de um quadro descritivo de um esquema proposto por Krupahtz (2018) que realiza um recorte do projeto audiovisual como foco no projeto do departamento de arte e nas funções e tarefas a serem realizadas pelo designer de produção. Este modelo foi gerado a partir do esquema da metodologia projetual para produtos gráfico-impressos proposto por Matté (2004), que é originalmente pensada para execução de projetos de design.

Posto isto, esta pesquisa tem como objetivo aprimorar o esquema da sistematização de Krupahtz (2018) utilizando a gestão visual de projetos para iniciar a elaboração de um modelo visual.

Para se cumprir este objetivo principal inicialmente irá se contextualizar as áreas de audiovisual e gestão visual de projetos para tornar claro a interação entre as áreas. Então, será apresentado a sistematização feita por Krupahtz (2018), 
assim será possível analisar, contextualizar e aprimorar este modelo fazendo com que o mesmo gere melhores resultados com ferramentas da gestão visual de projetos.

\section{A GESTÃO VISUAL E O AUDIOVISUAL}

O processo de design é envolto por uma série de atividades e necessidades que surgem para agilizar e também para condensar informações com o intuito de auxiliar nos processos de tomada de decisão. A área de design pode assumir diversas formas, como a organização de estruturas organizacionais, processos operacionais e não somente objetos físicos concretos (STICKDORN E SCHNEIDER, 2014).

Estes processos podem envolver diversas áreas e equipes, por isso não existe um processo que seja ideal para todas as áreas, todos eles são moldados dependendo do tipo, finalidade e tamanho do projeto. A informação e a compreensão são premissas básicas em todos os projetos da área de design, uma vez que a informação precisa ser facilmente compreendida por todos os envolvidos (TEIXEIRA E MERINO, 2014).

Unir diversos processos e equipes multidisciplinares pode não ser uma tarefa fácil. Normalmente o processo precisa ser adaptado para cada cenário. No audiovisual, é recorrente o fato de que as equipes são compostas por profissionais de diversas áreas, já que o audiovisual em si não é uma área de estudo exclusiva do design. Por essa razão, reforça-se também a necessidade de facilitar o acompanhamento do projeto por todos os envolvidos para que o destino seja claramente identificável por todos. Neste sentido, as representações visuais são superiores às verbais, acabando por serem mais efetivas (BAUER E JOHNSON-LAIRD, 1993 e LARKIN E SIMON, 1987), principalmente em projetos nas 
áreas voltadas ou tangentes ao design.

Para Teixeira (2018), quanto mais visual for o processo maiores serão as chances de compreensão e também de tomada de decisão, podendo deixar os processos mais práticos e aderentes à inovação. A boa visualização das informações também pode auxiliar no processo de aprendizagem por parte dos envolvidos no projeto.

Os atores precisam ter a capacidade de observar o processo de forma global, conseguindo entender as principais etapas do processo, mesmo que não seja de sua área de atuação (TEIXEIRA, 2018). Para Sibbet (2013), as equipes tornam-se mais eficientes e eficazes quando conseguem observar a temática e desenvolver comparações, localização de padrões e mapeamentos, isso facilita o pensamento global acerca do projeto. Posto isso, encontra-se neste cenário a gestão visual de projetos, capaz de direcionar equipes e promover o maior entendimento por parte de todos os envolvidos.

Além da integração dos atores em um mesmo processo, a gestão visual também permite e estimula a cocriação durante o processo, "algo que é essencial para a sustentabilidade da satisfação tanto de usuários quanto de funcionários" (STICKDORN E SCHNEIDER, 2014, p. 41).

Para o melhor entendimento da gestão visual, pode-se adotar para este artigo a definição do Lean Institute Brasil que define gestão visual como "um sistema de planejamento, controle e melhoria contínua que integra ferramentas visuais simples que possibilitam que se entenda, através de uma rápida 'olhada', a situação atual".

O uso da gestão visual de projetos pode servir para melhoria no planejamento estratégico de projetos, projetando possibilidades visuais a todos os atores envolvidos. Este fato torna-se uma vantagem ao proporcionar o entendimento claro 
e transparente de todas as ações.

A melhoria no entendimento completo do processo também é uma vantagem que a gestão visual se compromete a entregar, principalmente ao envolver um grande fluxo de informações em diferentes níveis da organização (Figura 1) (TEIXEIRA, 2018).

Figura 1. Nível de Confusão

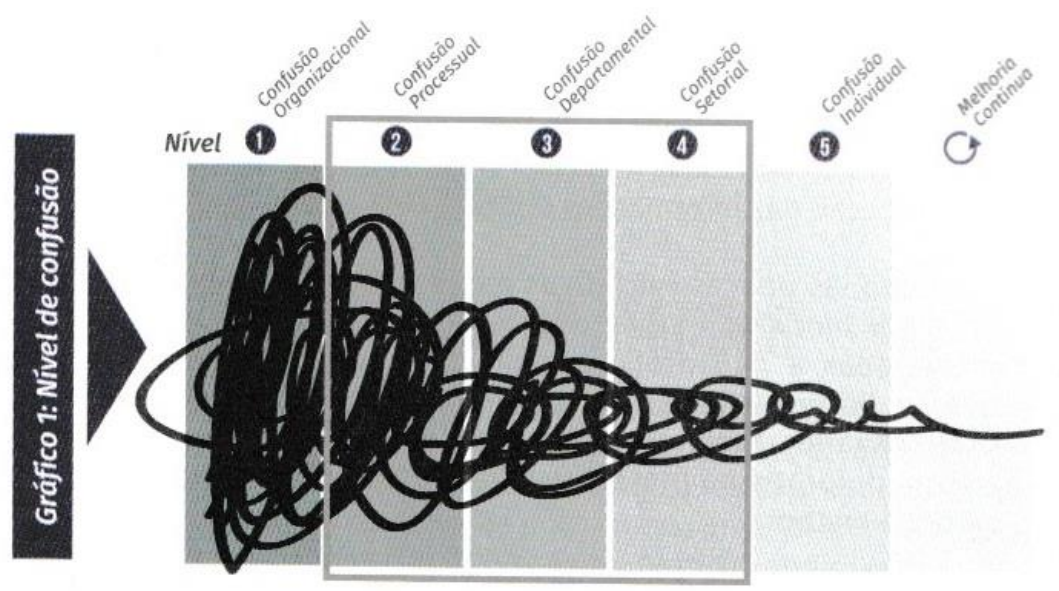

Fonte: TEIXEIRA (2018, p. 25)

No gráfico acima pode-se observar as dificuldades encontradas em processos que envolvam times complexos e de diferentes níveis na organização. Com esta dificuldade no entendimento o processo pode ser atrapalhado por conflitos baseados em mal-entendimentos, falhas de comunicação, erros de interpretação, frustrações e disputadas internas (TEIXEIRA, 2018)

Em um sistema complexo com envolvimentos de ativos importantes, como em uma produção audiovisual, onde existem muitas áreas e diversos atores que precisam coordenar esforços em sincronia, a gestão visual pode ser o carro chefe para guiar o processo durante sua execução. A gestão visual irá permitir a rápida compreensão do sistema e a descoberta de informações (DUSSE et al, 2016).

Não existe uma única forma de utilizar a gestão visual, pois 
ela é uma ferramenta dinâmica e adaptável em conjunto com vários modelos e metodologias. Teixeira (2018) propõe um modelo, sugerindo um sistema baseado em representações visuais para melhor prática da gestão, mencionando premissas e funções que devem fazer parte da gestão visual de projetos. Entre tais pode-se destacar o uso de painéis visuais que não buscam detalhar cada aspecto do modelo, mas sim fornecer uma visão geral. O autor também salienta o que pode ser utilizado como fonte de informação, isso inclui desde cores, fontes e formas até mesmo elementos textuais e numéricos. Ao final propõe um roteiro (roadmap) com orientações para a construção de um modelo visual que servirá de suporte para a gestão visual.

\subsection{Método Lemming}

Para os estudos do presente artigo, portanto, optou-se por utilizar o método de estruturação do Lemming proposto por Teixeira (2018). Este método também servirá como procedimento metodológico para apoio à pesquisa. De acordo com o autor, ele serve como suporte à gestão visual para o desenvolvimento de projetos variados.

Este método também se caracteriza por ser "uma proposta que visa disseminar princípios, valores e ferramentas que preconizam a visualização de informações e o pensamento visual" (WERNKE, 2017, p.54).

Em sua proposta de estruturação Teixeira (2018) descreve algumas premissas para a proposta de gestão visual de projetos (Figura 2), como: priorizar a visualização no processo, desenvolver estratégias visuais que sejam aplicadas desde o planejamento, elaboração de planos de ação a partir de diagramas, ter alternativas de visualização, valorizar a análise visual e promover a interação e a participação de toda 
a equipe.

Figura 2. Premissas Lemming

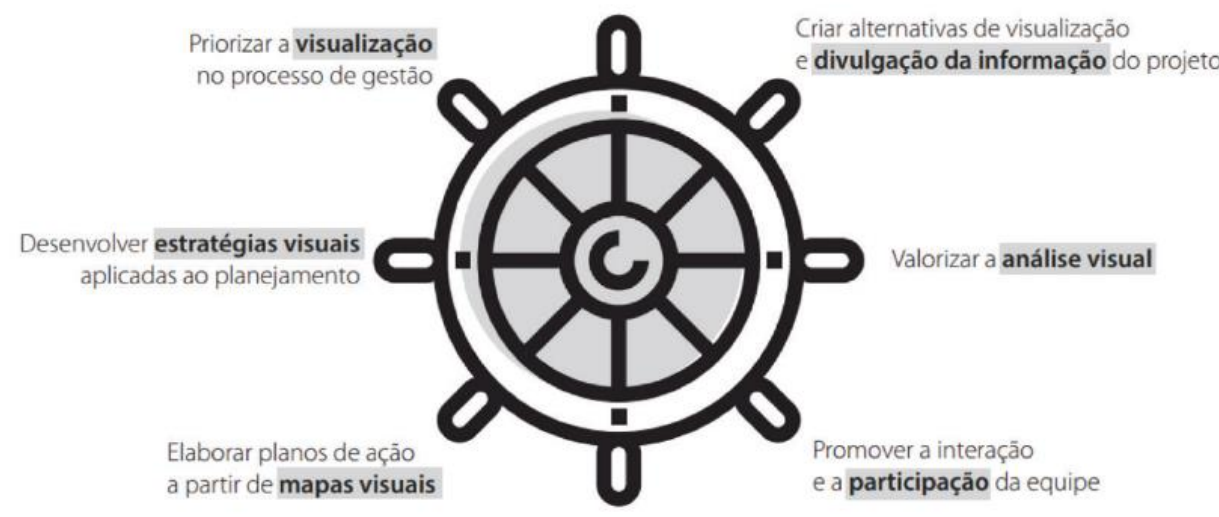

Fonte: Wernke (2017, p.54)

O método Lemming é composto por cinco etapas denominadas de sprints, e desenvolvido para se adaptar a inúmeros projetos, principalmente na área de design. $\mathrm{Na}$ figura abaixo (Figura 3 ) observa-se que em cada etapa quanto maior o grau da visão geral do projeto, menor será o detalhamento específico de cada etapa. Quanto menor a visão global, maior será o nível de detalhamento de cada etapa.

Figura 3. Ferramentas da gestão visual de projetos

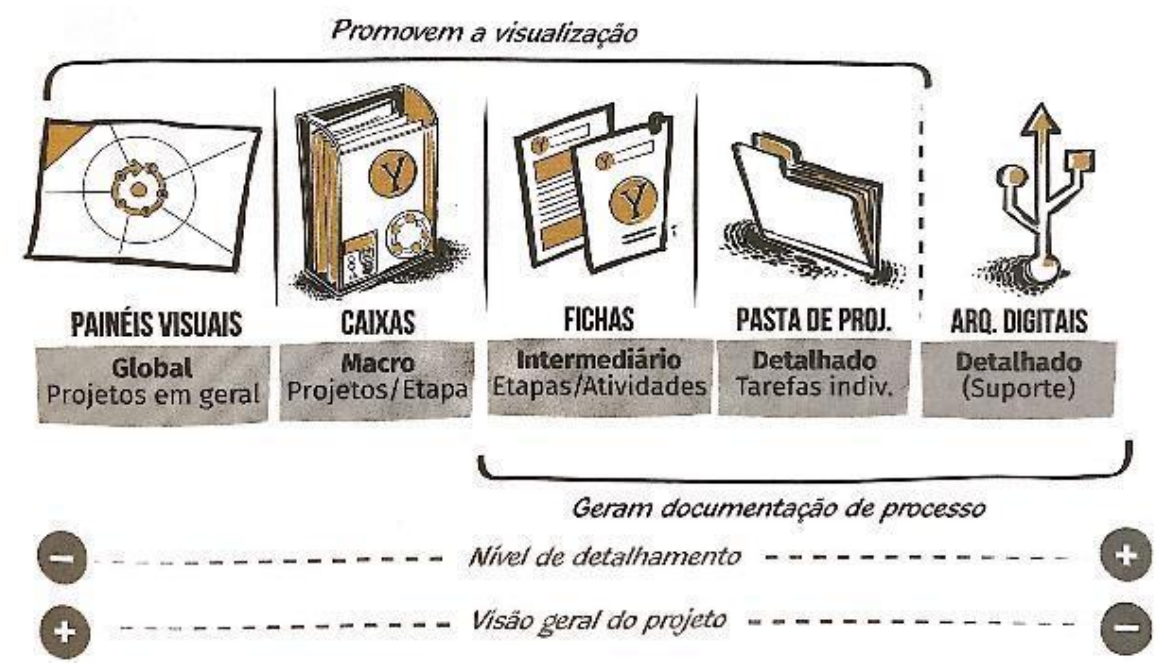

Fonte: TEIXEIRA (2018, p. 103)

Na etapa inicial - Quadro Descritivo - é necessário a 
seleção de um modelo de referência, sendo baseado na descrição de etapas de forma detalhada. Torna-se possível, por exemplo, utilizar como base perguntas centrais, como (i) o quê?, (ii) por quê? e (iii) como fazer?, de maneira que construam um modelo visual e preencham um quadro de etapas.

No sprint 1 - Quadro de Etapas - é confeccionado um quadro para descrever as etapas do processo em diferentes níveis de complexidade (WERNKE, 2017). Estes diferentes níveis podem ir de global, passando por intermediário e detalhado (TEIXEIRA, 2018).

No sprint 2 - Pensamento Visual - serão iniciadas as análises das ferramentas visuais que serão empregadas no projeto. Nesta etapa, incorpora-se a gestão visual como meio de tornar mais visual cada etapa, e também, as caixas de projeto onde contém as fichas de orientação de cada etapa. As fichas de orientação têm o intuito de auxiliar o entendimento de todas as atividades que serão elaboradas. É também a etapa onde acontece a construção de um painel visual, cuja principal função é estimular as equipes a promoverem a interação com o modelo e com o projeto, passando de maneira simples a informação a todos os membros. Estes painéis ainda podem ser desdobrados em: (a) fixo; (b) móvel; (c) equipe; (d) atividades; (d) cronograma visual e; (e) cartão recado. Cada um com sua melhor interação, utilizados sempre conforme a prioridade e a melhor interação para cada projeto.

Na etapa de sprint 3 - Detalhamento de Ferramentas - são utilizadas pastas de projetos, as quais são uma prática para acondicionar documentos físicos. Nelas contém as fichas de orientação e também as fichas de saída, que deverão ser preenchidas ao final de cada etapa, com propósito de promover uma síntese visual para a etapa seguinte. 
A última etapa, sprint 4 - Prototipação e Implementação - tornam-se recursos para suporte a gestão, devem sempre ser atualizadas e compartilhadas entre os membros das equipes de maneira detalhada. Sendo assim, entende-se que a melhor maneira para a execução desta etapa é por meio da utilização de arquivos digitais.

Figura 4. Roadmap para um modelo visual

\section{ROADMAP PARA UM MODELO VISUAL}

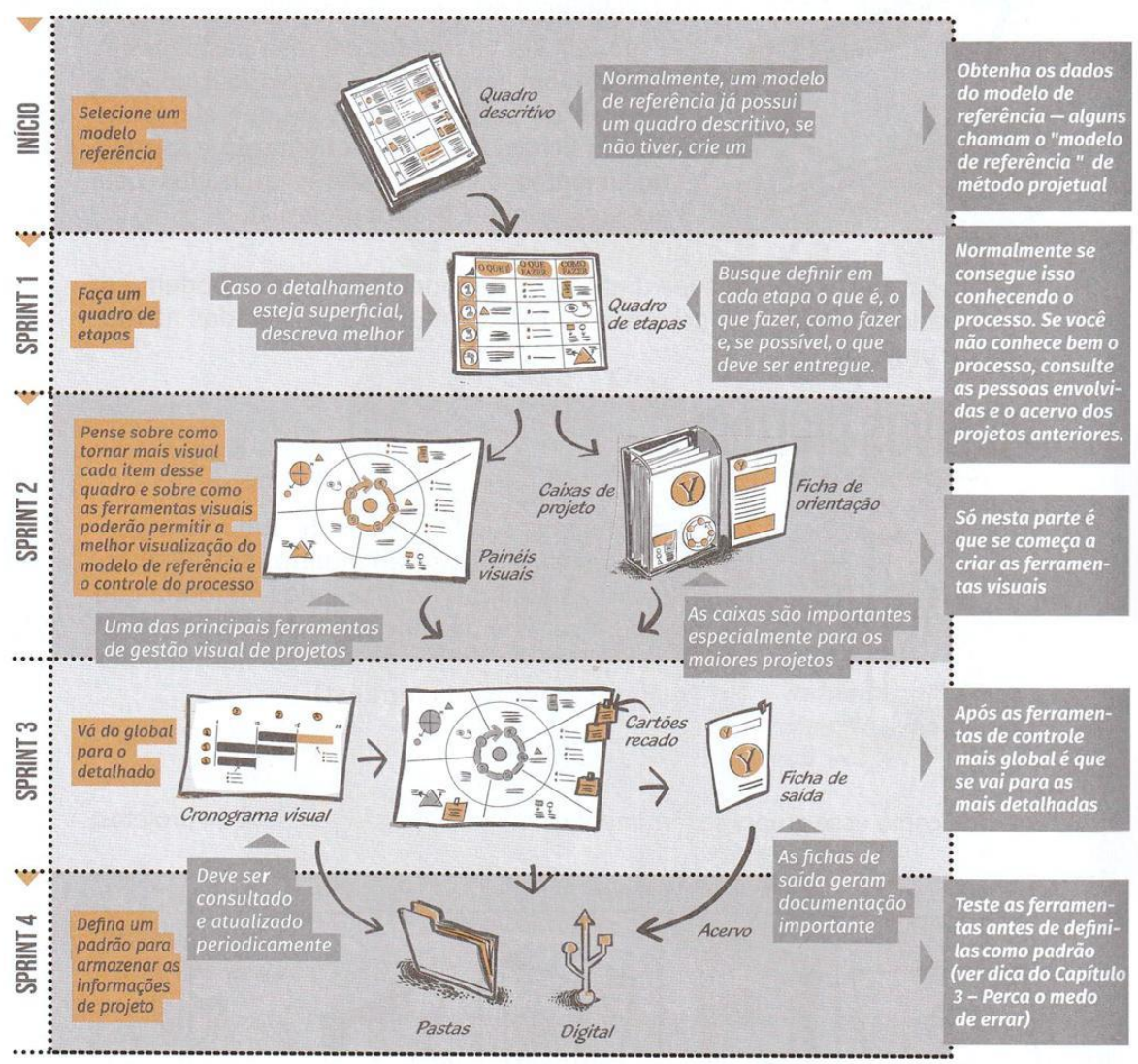

Fonte: TEIXEIRA (2018, p. 104).

Na figura acima encontra-se um modelo visual do método Lemming para a gestão visual de projetos. Teixeira (2018) ainda alerta para a necessidade de prototipar e adaptar o modelo de acordo com cada necessidade, valorizando sempre a melhor interação e usabilidade com os usuários. 


\subsection{0 projeto audiovisual sob a perspectiva do designer de produção}

O design de produção é o setor do audiovisual e do cinema responsável pela composição visual do filme, incluindo a disposição de cenários, móveis e objetos e as suas relações com os atores (BAPTISTA, 2008). O designer de produção é o profissional encarregado de coordenar todo o departamento de arte, além da criação, execução e coerência do projeto.

Considerando-se os pontos levantados na seção anterior, entende-se que a gestão visual de projetos pode colaborar de forma significativa para uma melhor compreensão e visualização de todo o processo criativo, principalmente nos casos que envolvem equipes maiores.

Ao iniciar um projeto audiovisual, a primeira fase é a de pré-produção. Nela, as primeiras ideias começarão a ser validadas e é organizado tudo aquilo que será necessário para a fase seguinte, a produção, ou seja, a filmagem. Quanto melhor for o trabalho desempenhado neste período do projeto, melhor será o restante do processo. De maneira geral, além da criação ou aprovação de um roteiro já pronto, também é organizado o orçamento necessário, a definição dos membros da equipe, a busca por possíveis locações, escolha de elenco, preparação de aspectos legais (documentações, contratos, seguros de equipamentos), cronograma de gravações, locação/definição de equipamento, entre outros. Nessa fase do projeto também acontece a criação do conceito visual do filme. Em razão disso, esta é a fase que mais se assemelha ao processo criativo do design ao mesmo tempo que deve ser muito bem executada e planejada, para que as chances de retrabalho e prejuízos sejam minimizadas.

O esquema da sistematização feito por Krupahtz (2018) foi 
construído dando enfoque ao projeto audiovisual realizado pelo designer de produção e a equipe do departamento de arte, tendo como base a metodologia projetual para produtos gráfico-impressos de Matté (2004) para a fase de préprodução. O modelo completo ainda contempla as fases de produção e pós-produção de maneira mais simplificada, porém para esta pesquisa decidiu-se abordar somente a préprodução (Figura 5), por ser a fase com maior proposta criativa.

Figura 5. Sistematização da pré-produção

\begin{tabular}{|c|c|c|c|c|c|}
\hline & \multirow[t]{2}{*}{ FASES } & \multirow{2}{*}{$\begin{array}{l}\text { ETAPAS } \\
\text { PROBLEMATIZAÇÃO }\end{array}$} & \multirow{2}{*}{$\begin{array}{l}\text { ATIVIDADES } \\
\text { EKPOSIÇÃO } \\
\text { DO PROBLEMA } \\
\text { PROGRAMA }\end{array}$} & \multirow{2}{*}{$\begin{array}{l}\text { TAREFAS } \\
\text { RECEBER ARGUMENTO } \\
\text { E ROTEIRO } \\
\text { DECUPAR, PLANEJAR } \\
\text { CRONOGRAMA E EQUIPE }\end{array}$} & \multirow{2}{*}{$\begin{array}{l}\text { DOCUMENTOS } \\
\text { LISTA DE CHECAGEM: } \\
\text { ELENCO, FIGURINO, } \\
\text { LOCAÇÕES E OBJETOS }\end{array}$} \\
\hline & & & & & \\
\hline & \multirow[t]{2}{*}{$\begin{array}{l}\text { COMPR. } \\
\text { DO PROJETO }\end{array}$} & PESQUISA & $\begin{array}{l}\text { DIACRÔNICA } \\
\text { G SINCRÔNICA } \\
\text { ASPECTOS } \\
\text { MERCADOLÓGICOS }\end{array}$ & $\begin{array}{l}\text { PROCURAR REFERÊNCIAS, } \\
\text { TEMA/ASSUNTO, HISTÓRIA } \\
\text { INVESTIGAR PÚBLICO } \\
\text { E MEIOS DE DIVULGAÇÃO }\end{array}$ & $\begin{array}{l}\text { MAPA DE } \\
\text { PERSONAGENS }\end{array}$ \\
\hline $\begin{array}{l}P \\
R \\
\text { R }\end{array}$ & & ANÁLISE & $\begin{array}{l}\text { FORMAL } \\
\text { E INFORMACIONAL }\end{array}$ & $\begin{array}{l}\text { ANALISAR COR, PERSONAGENS, } \\
\text { FIGURINO, LOCAÇÕES, } \\
\text { OBJETOS, DESIGN GRÁFICO, } \\
\text { MATERIAL DE DIVULGAÇÃO }\end{array}$ & \\
\hline $\begin{array}{l}- \\
P \\
R \\
O\end{array}$ & \multirow[t]{2}{*}{$\begin{array}{l}\text { CONFIG. } \\
\text { DO PROJETO }\end{array}$} & DEFINIÇÃO & $\begin{array}{l}\text { LISTA DE REQUISITOS } \\
\text { REDEFINIÇ̃̃o } \\
\text { DO PROBLEMA }\end{array}$ & $\begin{array}{l}\text { DEFINIR OBRIGATÓRIOS, } \\
\text { DESEJÁVEIS, OPCIONAIS } \\
\text { ESBOÇAR COM TEXTOS, } \\
\text { ESQUEMAS E DIAGRAMAS } \\
\text { DESENHAR STORYBOARD }\end{array}$ & $\begin{array}{l}\text { PREVISÃO } \\
\text { DE DESPESAS }\end{array}$ \\
\hline $\begin{array}{l}\text { U } \\
\text { Ç } \\
\tilde{A}\end{array}$ & & $\begin{array}{l}\text { MODELAÇÃO } \\
\text { INICIAL }\end{array}$ & $\begin{array}{l}\text { RASTREIO } \\
\text { MODELOS INICIAIS/ } \\
\text { INTERMEDIÁ RIOS }\end{array}$ & $\begin{array}{l}\text { PROCURAR LOCAÇÕES, } \\
\text { FIGURINO, OBJETOS, ELENCO } \\
\text { REALIZAR APRESENTAÇÃO } \\
\text { INICIAL }\end{array}$ & \\
\hline & \multirow[t]{2}{*}{$\begin{array}{l}\text { REALIZAÇÃO } \\
\text { DO PROJETO }\end{array}$} & $\begin{array}{l}\text { MODELAÇÃO } \\
\text { FINAL }\end{array}$ & MODELOS FINAIS & GRAVAR ANIMATIC & \\
\hline & & NORMATIZAÇÃO & $\begin{array}{l}\text { CODIFICAÇÃO } \\
\text { PARA PRODUÇÃO } \\
\text { DESCRIÇÃO TÉCNICA } \\
\text { DE PRODUÇÃO }\end{array}$ & $\begin{array}{l}\text { REALIZAR } \\
\text { APRESENTAÇÃO FINAL } \\
\text { ENCAMINHAR } \\
\text { PARA COMPRA/ } \\
\text { PRODUÇÃO DE ARTE }\end{array}$ & $\begin{array}{l}\text { LISTA DE CRÉDITOS, } \\
\text { LISTA DE CHECAGEM: } \\
\text { PRÉ-FILMAGEM }\end{array}$ \\
\hline
\end{tabular}

Fonte: KRUPAHTZ (2018, p. 55).

O esquema apresentado pela autora como uma "Sistematização de atividades, tarefas e documentos para o projeto audiovisual" utiliza como base as metodologias de Matté (2004) e Rodrigues (2007) respectivamente para estrutura das fases de produção e pós-produção. Acredita-se 
que essa proposta pode ser aprimorada se construída com os princípios da gestão visual de projetos. Logo, foi escolhido o quadro da Figura 5 para representar o quadro descritivo da etapa inicial do Método Lemming, sendo então desenvolvido um quadro de etapas e por fim, um painel visual.

\section{RESULTADOS}

A construção deste painel visual pode ser entendida como um novo artefato para a solução do objetivo proposto. Gill e Hevner (2011, p. 238) definem artefatos como "[...] uma representação simbólica ou uma instanciação física dos conceitos de design.". Tal artefato tem sua base fundamental ancorada em Design Science Research, uma vez que este método sugere que o pesquisador possa explorar diversos artefatos e então construir algo novo ou utilizar um artefato já existente (DRESCH; LACERDA; ANTUNES JUNIOR, 2015). Para o desenvolvimento desta solução, escolheu-se desenvolver um novo artefato como apoio a um método já existente - Método Lemming. Este painel visual pode ser classificado como um artefato de método. Esta classificação, de acordo com Dresch, Lacerda e Antunes Junior (2015) refere-se ao conjunto de passos necessários para cumprir-se uma tarefa. Tais passos, ou etapas, podem ter representação gráfica ou serem envolvidos em heurísticas e algoritmos específicos (DRESCH; LACERDA; ANTUNES JUNIOR, 2015, p. 112).

$\mathrm{Na}$ construção de um artefato, Gill e Hevner (2011) sugerem algumas camadas para este processo. Na primeira camada encontra-se o espaço do design, que é a análise de "possíveis soluções para o problema, ou seja, os possíveis artefatos a serem desenvolvidos, bem como os requisitos para seu bom funcionamento." (DRESCH; LACERDA; ANTUNES 
JUNIOR, 2015, p.109). Após a escolha da solução, passa-se a segunda camada, denominada de desenvolvimento do artefato. Esta é propriamente a construção do artefato e pode ser subdividida em: viabilidade, utilidade, representação e construção do artefato. (DRESCH; LACERDA; ANTUNES JUNIOR, 2015). Na última camada, tem-se o uso do artefato que "visa prepará-lo para sua implementação e uso no ambiente real." (DRESCH; LACERDA; ANTUNES JUNIOR, 2015, p.109). Esta última camada também está subdividida em "instanciação piloto do artefato e liberação do artefato para instanciação" (DRESCH; LACERDA; ANTUNES JUNIOR, 2015, p.109). A construção do painel visual (artefato) concentra-se principalmente na segunda camada, intitulada de desenvolvimento do artefato.

De acordo com o Método Lemming, no início do processo de construção de um modelo visual, conforme foi abordado na seção anterior, há o Quadro Descritivo, representado graficamente por Krupahtz (2018) na Figura 5. No quadro é possível observar algumas informações como fases, etapas, atividades, tarefas e documentos. Para a construção do Quadro de Etapas (Quadro 1) - sprint 1 - essas informações foram reescritas, detalhadas e reorganizadas de acordo com as seguintes categorias: (i) fase, (ii) etapa, (iii) o que é?, (iv) o que fazer?, (v) como fazer? e ainda (vi) o que entregar?. A última categoria foi adicionada como forma de organizar melhor a construção de futuras fichas de saída para cada etapa do projeto, o que é sugerido por Teixeira (2018), ao invés de agrupar em documentos, conforme foi feito no quadro original. Neste quadro, as etapas já foram organizadas por cores conforme as fases do projeto, para facilitar a construção do painel visual. 
Quadro 1. Quadro de etapas

\begin{tabular}{|c|c|c|c|c|c|}
\hline FASE & ETAPA & O QUE É? & O QUE FAZER? & COMO FAZER? & O QUE ENTREGAR? \\
\hline & \multirow[t]{5}{*}{ Problematização } & $\begin{array}{l}\text { 1A. Exposiçẫo ao } \\
\text { Problema }\end{array}$ & $\begin{array}{l}\text { Receber argumento e } \\
\text { roteiro }\end{array}$ & $\begin{array}{l}\text { Providenciar roteiro impresso com o núcleo } \\
\text { principal }\end{array}$ & Roteiro impresso \\
\hline & & \multirow[t]{4}{*}{ 18. Programa } & Decupar roteiro & $\begin{array}{l}\text { Destacar os pontos que identificam } \\
\text { caracteristicas visuais do filme, como figurinos, } \\
\text { ambientes, caracteristicas de personagens, } \\
\text { objetos, entre outros. }\end{array}$ & Roteiro impresso decupado \\
\hline & & & \begin{tabular}{|l|}
$\begin{array}{l}\text { Preencher lista de } \\
\text { checagem }\end{array}$ \\
\end{tabular} & $\begin{array}{l}\text { Identificar elementos extraidos do processo de } \\
\text { decupagem de roteiro }\end{array}$ & Lista de checagem preenchida \\
\hline & & & Planejar cronograma & $\begin{array}{l}\text { Preencher cronograma visual e anexar ao } \\
\text { painel }\end{array}$ & Cronograma visual preenchido \\
\hline & & & Organizar equipe & Contratar equipe e distribuir funçб̃es & $\begin{array}{l}\text { Lista com nomes dos membros da } \\
\text { equipe de projeto e suas } \\
\text { respectivas funções }\end{array}$ \\
\hline \multirow{11}{*}{ 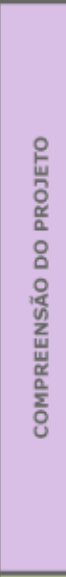 } & \multirow[t]{4}{*}{ 2. Pesquisa } & \multirow{3}{*}{$\begin{array}{l}\text { 2A. Diacrônica e } \\
\text { Sincrônica }\end{array}$} & Pesquisar referências & \multirow{3}{*}{$\begin{array}{l}\text { Agrupar informações e imagens coletadas em } \\
\text { um único documento, que pode ser um } \\
\text { moodboard exposto em uma sala da equipe, } \\
\text { junto com o painel visual }\end{array}$} & \multirow{3}{*}{$\begin{array}{l}\text { Moodboard de referências visuais } \\
\text { com anotaç̧̋es sobre assuntos e } \\
\text { contexto histórico abordados pelo } \\
\text { roteiro }\end{array}$} \\
\hline & & & $\begin{array}{l}\text { Pesquisar tema/assuntos } \\
\text { abordados }\end{array}$ & & \\
\hline & & & $\begin{array}{l}\text { Pesquisar contexto } \\
\text { histórico }\end{array}$ & & \\
\hline & & $\begin{array}{l}\text { 2B. Aspectos } \\
\text { mercadológicos }\end{array}$ & $\begin{array}{l}\text { Investigar público e meios } \\
\text { de divulgaçăo }\end{array}$ & $\begin{array}{l}\text { Gerar um relatório de mercado e principais } \\
\text { plataformas que serão utilizadas para a } \\
\text { divulgação }\end{array}$ & $\begin{array}{l}\text { Relatório de mercado e meios de } \\
\text { divulgação }\end{array}$ \\
\hline & \multirow[t]{7}{*}{ 3. Análise } & \multirow{7}{*}{$\begin{array}{l}\text { 3A. Formal e } \\
\text { Informacional }\end{array}$} & Analisar cor & \multirow{6}{*}{$\begin{array}{l}\text { Separar uma amostra de principais trabalhos } \\
\text { como referência, levantados na etapa de } \\
\text { pesquisa e analisar cada um dos aspectos } \\
\text { elencados. Por fim, unificar todos na ficha de } \\
\text { saida. }\end{array}$} & \multirow{6}{*}{$\begin{array}{l}\text { Análises dos elementos dos } \\
\text { trabalhos selecionados }\end{array}$} \\
\hline & & & Analisar personagens & & \\
\hline & & & Analisar figurinos & & \\
\hline & & & Analisar locações & & \\
\hline & & & Analisar design gráfico & & \\
\hline & & & $\begin{array}{l}\text { Analisar material de } \\
\text { divulgação }\end{array}$ & & \\
\hline & & & $\begin{array}{l}\text { Preencher mapa de } \\
\text { personagens }\end{array}$ & $\begin{array}{l}\text { Com base nas referências, preencher ficha de } \\
\text { mapa de personagens, com caracteristicas } \\
\text { anexando imagens como referencial, podendo } \\
\text { ser esboços ou figuras. }\end{array}$ & $\begin{array}{l}\text { Mapa de personagens preenchido, } \\
\text { com imagens e esboços anexados }\end{array}$ \\
\hline \multirow{8}{*}{ 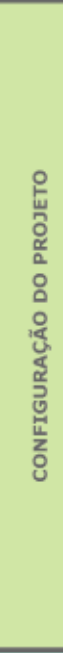 } & \multirow[t]{4}{*}{ 4. Definição } & \multirow[t]{2}{*}{$\begin{array}{l}\text { 4A. Lista de } \\
\text { Requisitos }\end{array}$} & $\begin{array}{l}\text { Definir requisitos } \\
\text { obrigatórios, desejáveis e } \\
\text { opcionais }\end{array}$ & $\begin{array}{l}\text { Preencher lista de requisitos conforme as } \\
\text { possibilidades e limitaçães do projeto }\end{array}$ & Lista de requisitos preenchida \\
\hline & & & Definir despesas & $\begin{array}{l}\begin{array}{l}\text { Iniciar o preenchimento da lista de previsão de } \\
\text { despesas }\end{array} \\
\end{array}$ & $\begin{array}{l}\text { Lista de previsão de despesas } \\
\text { preenchida }\end{array}$ \\
\hline & & \multirow[t]{2}{*}{$\begin{array}{l}\text { 4B. Redefinição } \\
\text { do problema }\end{array}$} & $\begin{array}{l}\text { Esboçar com textos, } \\
\text { esquemas e diagramas }\end{array}$ & $\begin{array}{l}\text { Colocar as ideias no papel, se necessário } \\
\text { imprimir e agrupar referências visuais } \\
\text { coletadas na etapa } 2 \text {. }\end{array}$ & $\begin{array}{l}\text { Esboços e anotações sobre o } \\
\text { conceito do filme }\end{array}$ \\
\hline & & & Construir storyboard & $\begin{array}{l}\text { Utilizar malha de storyboard para esboçar } \\
\text { enquadramentos e visualizaçóes de aspectos } \\
\text { fisicos da filmagem }\end{array}$ & Storyboard \\
\hline & \multirow[t]{4}{*}{$\begin{array}{l}\text { 5. Modelaçăo } \\
\text { Inicial }\end{array}$} & \multirow[t]{3}{*}{ 5A. Rastreio } & Procurar locaçöes & $\begin{array}{l}\text { Com base nas referências, catalogar e } \\
\text { registrar possiveis locaçôes }\end{array}$ & $\begin{array}{l}\text { Relação de locações com fotos, } \\
\text { endereços, valores, contatos, } \\
\text { vantagens e desvantagens }\end{array}$ \\
\hline & & & $\begin{array}{l}\text { Procurar figurinos e } \\
\text { objetos }\end{array}$ & $\begin{array}{l}\text { Adquirir peças, esboçar figurinos que precisam } \\
\text { ser produzidos e realizar parcerias com } \\
\text { fornecedores }\end{array}$ & $\begin{array}{l}\text { Esboços de figurinos e contatos de } \\
\text { parcerias feitas }\end{array}$ \\
\hline & & & Procurar elenco & $\begin{array}{l}\text { Acompanhar testes de elenco realizados pelo } \\
\text { departamento de casting e verificar se } \\
\text { atendem os requisitos definidos para os } \\
\text { personagens }\end{array}$ & $\begin{array}{l}\text { Nomes e fotos de atores } \\
\text { contratados. Anotar medidas de } \\
\text { figurino na lista de checagem } \\
\text { inicial. }\end{array}$ \\
\hline & & $\begin{array}{l}\text { 5B. Modelos } \\
\text { iniciais / } \\
\text { intermediários }\end{array}$ & $\begin{array}{l}\text { Realizar apresentação } \\
\text { inicial }\end{array}$ & $\begin{array}{l}\text { Agrupar toda a documentação gerada e } \\
\text { apresentar o conceito para o núcleo principal } \\
\text { da equipe. Documentar alteraçães necessárias } \\
\text { e repassar relatórios à produção, }\end{array}$ & $\begin{array}{l}\text { Documentação do projeto } \\
\text { catalogada }\end{array}$ \\
\hline \multirow{5}{*}{ 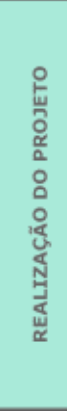 } & $\begin{array}{l}\text { 6. Modelaçăo } \\
\text { final }\end{array}$ & 6A. Modelos finais & Gravar animatic & $\begin{array}{l}\text { Realizar filmagem nas locações já escolhidas, } \\
\text { podendo ser com o elenco contratado ou não, } \\
\text { com equipamento simplificado, para testar } \\
\text { enquadramentos e elencar possiveis mudanças } \\
\text { visuais. }\end{array}$ & Animatic \\
\hline & \multirow[t]{4}{*}{ 7. Normatização } & $\begin{array}{l}\text { 7A. Codificação } \\
\text { para a produção }\end{array}$ & Realizar apresentação final & $\begin{array}{l}\text { Agrupar documentação com alteraçōes e } \\
\text { animatic para apresentar novo conceito à } \\
\text { equipe }\end{array}$ & $\begin{array}{l}\text { Documentaçẫo do projeto } \\
\text { atualizada }\end{array}$ \\
\hline & & \multirow[t]{3}{*}{$\begin{array}{l}\text { 7B. Descrição } \\
\text { técnica de } \\
\text { produçăo }\end{array}$} & $\begin{array}{l}\text { Encaminhar para compra } \\
\text { ou produçăo de arte }\end{array}$ & $\begin{array}{l}\text { Delegar tarefas de compra ou produção de } \\
\text { arte de todos os itens elencados para a } \\
\text { produçăo }\end{array}$ & $\begin{array}{l}\text { Relação de responsáveis por cada } \\
\text { tarefa e relaçăo de itens já } \\
\text { adquiridos ou produzidos }\end{array}$ \\
\hline & & & Preencher lista de créditos & $\begin{array}{l}\text { Registrar parcerias, profissionais envolvidos, } \\
\text { voluntários e equipe envolvida no projeto }\end{array}$ & Lista de créditos preenchida \\
\hline & & & $\begin{array}{l}\text { Preencher lista de } \\
\text { checagem pré-filmagem }\end{array}$ & $\begin{array}{l}\text { Organizar itens necessários conforme } \\
\text { cronograma de produção e armazenar } \\
\text { devidamente para o transporte }\end{array}$ & $\begin{array}{l}\text { Lista de checagem pré-filmagem } \\
\text { preenchida e itens organizados } \\
\text { para a produçăo }\end{array}$ \\
\hline
\end{tabular}

Fonte: autores (2020).

No sprint 2, as ferramentas visuais são criadas. Podendo 
ser painéis visuais, caixas, fichas, entre outras já citadas. Para o presente artigo, optou-se por desenhar um painel visual (Figura 6) que pode ser utilizado como painel de equipe ou painel fixo. Ele promove uma visualização mais ampla de todas as tarefas que devem ser executadas na fase de préprodução e utiliza as mesmas cores e informações já contidas no quadro de etapas, porém organizadas de maneira visual em uma estrutura radial.

Figura 6. Painel visual da pré-produção

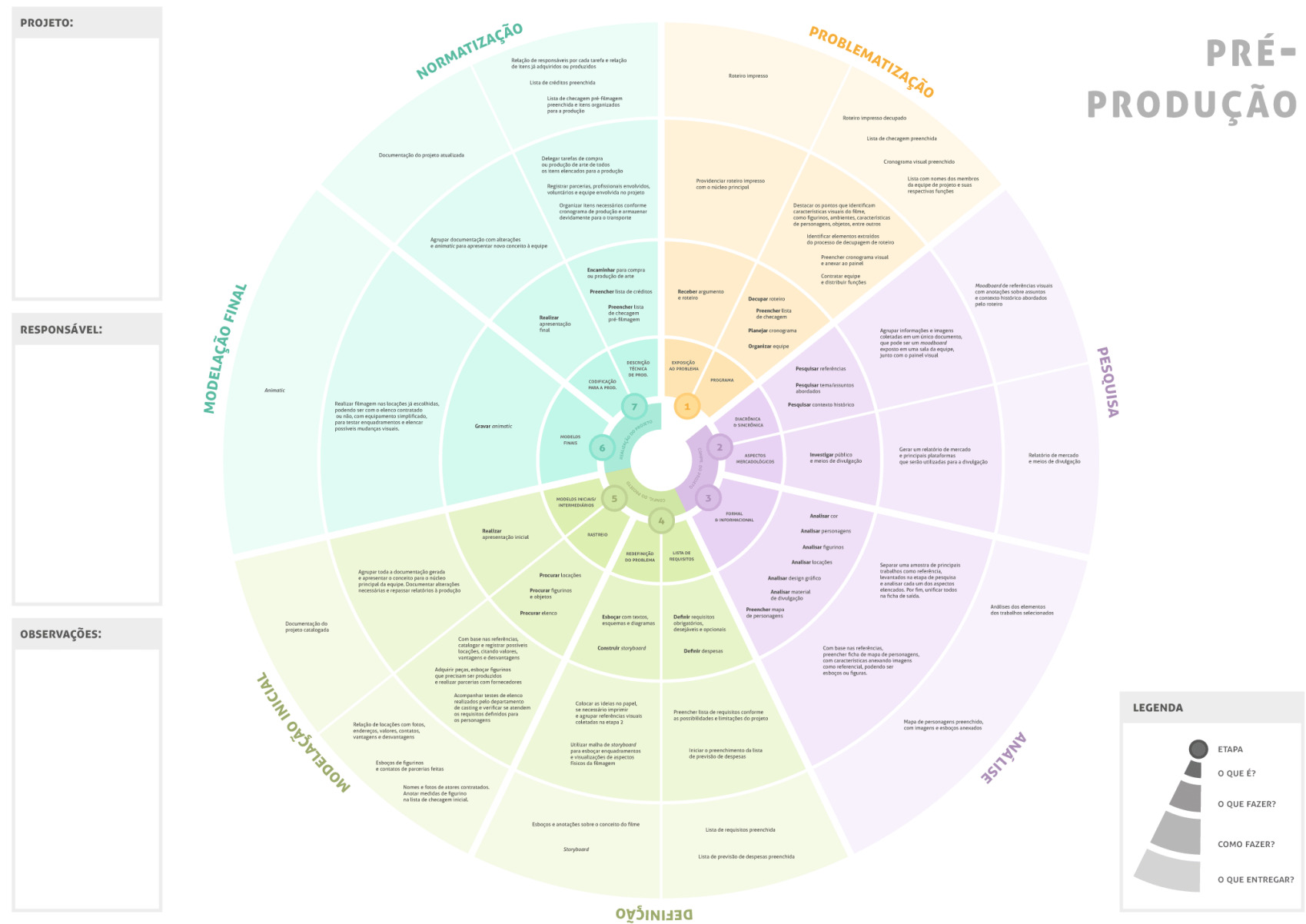

Fonte: autores (2020).

Com todas as fases, etapas e tarefas descritas em somente um esquema visual, as informações ficam acessíveis de maneira simultânea por todos os integrantes da equipe. No caso da utilização como um painel fixo, a prancha pode ser 
impressa e disponibilizada no ambiente de trabalho, assim os profissionais podem interagir com o esquema de forma gráfica, adicionando bilhetes e riscando ao cumprirem as tarefas.

Decidiu-se por diagramar o painel visual em uma prancha tamanho A2, que pode ser impresso facilmente por diversas gráficas. No caso da utilização como um painel de equipe, pode ser impresso em um formato menor para que seja mais viável ao transporte. Dessa forma, pode acompanhar os profissionais nas locações durante as filmagens, permitindo o acompanhamento até a conclusão de todas as tarefas.

$\mathrm{Na}$ folha, além da imagem do painel visual há também campos para preenchimento manual com o nome do projeto, responsável - que se entende como o designer de produção da equipe - e observações. No canto inferior direito foi colocado uma legenda com a descrição da organização das categorias para uma melhor compreensão do gráfico.

\section{CONSIDERAÇÕES FINAIS}

Apesar do esquema proposto por Krupahtz (2018) não se caracterizar como uma metodologia em si, e sim uma sistematização feita a partir de uma adaptação de outras metodologias, é possível perceber a melhoria da visualização do processo criativo do departamento de arte e do design de produção de toda a fase de pré-produção do audiovisual. Acredita-se que com mais trabalhos abordando o mesmo tema e existindo a contínua aplicação de outras ferramentas da gestão visual de projetos nesse mesmo modelo possa-se evoluir e aprimorar ainda mais o processo como um todo, incluindo as fases de produção e pós-produção.

A Design Science Research pode ser utilizada como um elemento auxiliador do processo de resultado, tendo maior 
influência na construção do artefato e sua sistematização, para gerar uma solução para o objetivo proposto. Com a utilização das heurísticas da Design Science Research foi possível encontrar uma solução desejável e passível de posterior validação. Recomenda-se que para trabalhos futuros, mantenha-se a utilização da Design Science Research nas outras camadas de construção. Dessa forma, irá auxiliar também em futuros processos de validação com usuários deste painel e outras ferramentas que podem ser criadas.

Para essas ferramentas, acredita-se que melhoraria a experiência de uso do painel com a construção de fichas de orientação e fichas de saída para cada uma das etapas de projeto pode-se gerar ferramentas importantes para registro de todo o material produzido. Portanto como proposta para trabalhos futuros, sugere-se que além da criação destas ferramentas, que seus desenhos especifiquem setores do departamento de arte, como figurino, maquiagem e cenário, já que a imagem do modelo foi construída para possibilitar a visualização do processo de toda a equipe, não somente do designer de produção.

Como forma de facilitar esse futuro trabalho de criação, esta pesquisa preocupou-se em apontar quais os resultados de cada etapa com a categoria o que entregar? que aparece tanto no quadro de etapas quanto no painel visual. Acreditase que a união dos elementos atribuídos a essa categoria em uma única ficha de saída por etapa possa ser o melhor caminho para a construção dessa ferramenta, assim facilitase 0 armazenamento dos documentos e a entrega dos mesmos à equipe de produção.

Além da proposta deste presente artigo, a construção de metodologias criadas a partir dos conceitos da gestão visual de projetos, todavia pensada especificamente para produtos audiovisuais podem ser de grande valia para os profissionais 
do design, principalmente se estas tiverem como enfoque o design de produção e o departamento de arte, um setor da equipe audiovisual que possui grande afinidade em termos de processo criativo com o design.

Desta forma, com um número cada vez maior de pesquisas tendo este tema como base, espera-se estimular a presença de profissionais do design ocupando estes espaços no mercado audiovisual.

\section{REFERÊNCIAS}

BAUER, Malcolm; JOHNSON-LAIRD, Philip. (1993). How diagrams can improve reasoning. Psychological Science, v.4, n.6, p.372-378, nov. 1993. Disponível em: https://www.jstor.org/stable/40062565?seq=1. Acesso em: 14 ago. 2020.

DUSSE, Flávio; JÚNIOR, Paulo Simões; ALVES, Antonia Tamires; NOVAIS, Renato; VIEIRA, Vaninha; MENDONÇA, Manoel. Information visualization for emergency management: A systematic mapping study. Expert Systems with Applications, 45(1), p.424$437 . \quad$ Disponível em: https://www.researchgate.net/publication/284017230_Information _visualization_for_emergency_management_A_systematic_mappi ng_study. Acesso em: 14 ago. 2020.

DRESCH, Aline; LACERDA, Daniel Pacheco; ANTUNES JUNIOR, José Antonio Valle. Design science research : método de pesquisa para avanço da ciência e tecnologia. Porto Alegre: Bookman, 2015. Epub.

GROVE, Elliot. Raindance producers' lab: lo-to-no budget filmmaking. Burlington, MA: Focal Press, 2004.

KRUPAHTZ, Juliana. O Design no Audiovisual: o papel do designer de produção no desenvolvimento de videoclipes. 2018. TCC (Graduação) - Curso de Desenho Industrial, Departamento de Desenho Industrial, Universidade Federal de Santa Maria, Santa Maria, 2018.

LARKIN, Jill; SIMON, Herbert. (1987). Why a diagram is (sometimes) worth ten thousand words. Cognitive Science, v.11, n.1, p.65-100, mar. 1987. Disponível em: https://onlinelibrary.wiley.com/doi/abs/10.1111/j.1551-

6708.1987.tb00863.x. Acesso em: 14 ago. 2020.

LEAN INSTITUTE BRASIL. Gestão Visual para apoiar o trabalho padrão das lideranças. Disponível em: https://www.lean.org.br/colunas/366/gestao-visual-para-apoiar-otrabalhopadrao-dasliderancas.aspx. Acesso em: 6 ago. 2020. LOBRUTTO, Vincent. The filmmaker's guide to production design. Nova Iorque: Allworth Press, 2002. 
MARTINS, Flavio Eduardo. Diretrizes para o desenvolvimento de dispositivos visuais em linhas de produção enxuta no setor automotivo. Dissertação (Mestrado). Universidade Federal do Paraná, Curitiba, 2006.

MATTÉ, Volnei. Proposta de metodologia projetual para produtos gráfico-impressos. Expressão. v.1, n.1, p.60-66, jul. 2004.

RODRIGUES, Chris. 0 cinema e a produção. 3 ed. Rio de Janeiro: Lamparina Editora, 2007.

STICKDORN, Marc; SCHNEIDER, Jakob. Isto é Design Thinking de Serviços: fundamentos, ferramentas, casos. Porto Alegre: Bookman, 2014.

TEIXEIRA, Júlio Monteiro. Gestão visual de projetos: utilizando a informação para inovar. Rio de Janeiro: Alta Books, 2018.

TEIXEIRA, Júlio Monteiro et al. Gestão Visual: uma proposta de modelo para facilitar o processo de desenvolvimento de produtos. Idemi: Conferência Internacional De Design, Engenharia e Gestão Para a Inovação. p. 01-09. Anais. Florianópolis: Idemi, 2012. Disponível em: http://juliomontex.com.br/wpcontent/uploads/2013/04/IDEMi_2012_Gestao_Visual.pdf. Acesso em: 10 ago. 2020.

WERNKE, Débora Verones. O Desenvolvimento de um Conjunto de Ferramentas Visuais para a Gestão de Projetos: um estudo de caso na empresa Bradda Design. 2012. 99 f. TCC (Graduação) Curso de Design, Centro de Comunicação e Expressão, Universidade Federal de Santa Catarina, Florianópolis, 2017. Disponível em: https://repositorio.ufsc.br/handle/123456789/192852. Acesso em: 12 ago. 2020. 